\title{
Natural ageing of aluminium processed by twist channel angular pressing
}

\author{
[LENKA KUNČICKÁ, RADIM KOCICH]
}

\begin{abstract}
The method of twist channel angular pressing (TCAP) was invented with the aim to increase the efficiency of single pass severe plastic deformation (SPD) technologies. The study shows the structure of TCAP-processed aluminium after processing and the changes developed in the structure after a year of natural ageing at room temperature. The grain refinement after a single pass TCAP was very significant due to effectively imposed shear strain; the majority of grains were smaller than $5 \mu \mathrm{m}$. The grains further showed sub-structure featuring fine precipitates, accumulated dislocations and developed subgrains. Transmission electron microscopy of the one-year-aged samples showed increased precipitation; the precipitates acted as effective obstacles for grain growth and structure recovery. The microscopy results were supplemented with microhardness measurements, the results of which showed a significant hardening for the single pass TCAP, after which the average microhardness increased from $44.6 \mathrm{HV}$ to more than 91 HV.
\end{abstract}

Keywords - twist channel angular pressing, sub-structure development, microhardness, ageing, aluminium

\section{Introduction}

The advantage of the severe plastic deformation (SPD) methods is primarily the ability to refine structural units by imposing shear strain, which results in the improvement of various material characteristics [1-3]. Due to their superior properties, materials processed by means of SPD can be used for various applications e.g. in electrotechnics [4], automotive [5], aircraft [6], military [7], as well as in biomedicine [8,9]. SPD is for example suitable for production of high-strength electro-conductive copper [10], consolidation of nano-scaled Al-based composites [11,12], improvement of corrosion resistance of pure $\mathrm{Mg}$ [13], enhancement of hydrogen sorption capacity of $\mathrm{Mg}$ [14], decreasing the elastic modulus of Tibased biocompatible alloys [15], and increasing the corrosion resistance of bio-applicable Mg-based alloys [16,17].

Among the mostly investigated SPD methods is equal channel angular pressing (ECAP), the amount of the simple shear strain imposed by which depends primarily on processing parameters, such as material characteristics, friction, processing temperature, die geometry, and the selected deformation route [18-23].

Lenka Kunčická, Radim Kocich

Regional Materials Science and Technology Centre

Vysoká Škola Báňská - Technical University of Ostrava

Czech Republic
Nevertheless, uniformity of strain distribution across the cross-section of a processed material after a single ECAP pass can be relatively low [24]. By this reason, an ECAP pass can advantageously be combined either with subsequent passes, or with another SPD component to increase the efficiency and imposed strain uniformity $[25,26]$. Considering ECAP-based methods, the structure refinement is generally greater with a higher imposed strain. However, after a very high amount of strain has been imposed, achievement of structure saturation characterized by the equilibrium between annihilation and generation of dislocations occurs. This significantly reduces any subsequent structure refining ability [27].

The technology of twist channel angular pressing (TCAP), which has recently been invented hand in hand with the contemporary trend of increasing the efficiency of SPD processes, is in principle a combination of ECAP and twist extrusion (TE) [28]. TE is another SPD method for which simple shear is the main deformation mechanism, however, non-uniformity of the imposed strain across the cross-section of a TE-processed material is evident [29-31]. Experimental and numerical studies published elsewhere showed the strain imposed during a single pass to be higher for TCAP, when compared to ECAP [28]. The method has a favourable influence on strain homogenization across the sample crosssection, too $[32,33]$. Previously published studies thoroughly investigated the influence of die geometry on the overall imposed strain [34], and compared grains orientations, misorientations and textures in materials processed by TCAP and various numbers of ECAP passes [35,36].

The main focus of this study was on characterization of sub-structure of a material processed by a single TCAP pass right after processing, and after a year of natural ageing at room temperature. The focus was on very fine strengthening structural features, such as grain boundaries, dislocations and precipitates. Structure studies via transmission electron microscopy were supplemented with grain size determination performed by means of scanning electron microscopy and microhardness measurements.

\section{Experimental}

As the experimental material, Commercial Purity (CP) aluminium (Al 99.7\%) was chosen. This material was selected primarily owing to its low flow stress and very high stacking fault energy (SFE), which provides $\mathrm{CP}$ Al with intrinsic material properties advantageous for demonstration of structural changes induced by SPD [37].

The $12 \times 12 \times 120 \mathrm{~mm}^{3}$ billets were firstly annealed for 1 hour at $400{ }^{\circ} \mathrm{C}$ to roughen the structure in order to better demonstrate the subsequent grain refinement. The TCAP extrusions were performed at room temperature using a 
NMT300 hydraulic press equipped with a specialized die (custom-made TCAP die, as depicted schematically in Fig. 1). The material was extruded at the rate of $3 \mathrm{~mm} \cdot \mathrm{s}^{-1}$ with $\mathrm{MoS}_{2}$ as the lubricant.

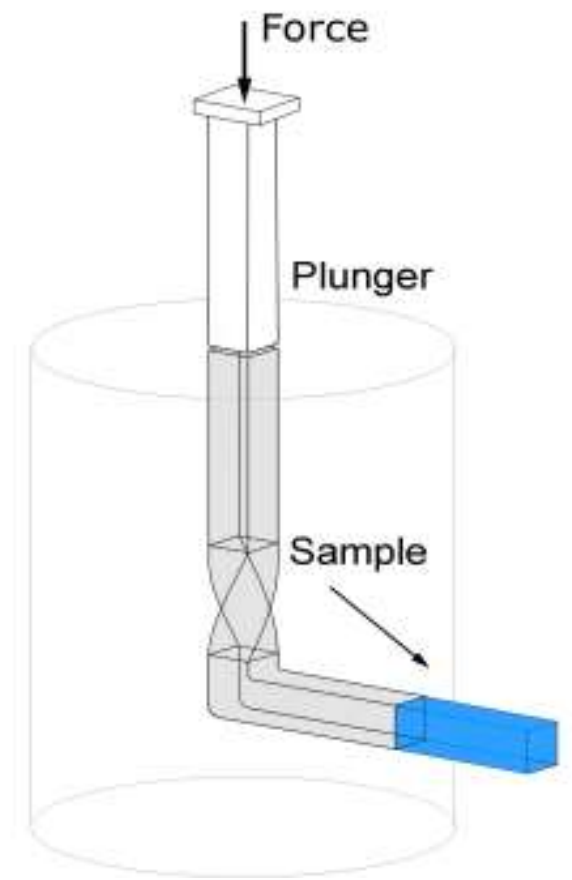

Figure 1. Schematic depiction of the TCAP die

After processing, rough samples for subsequent structure analyses were cut using a CNC electro-erosive wire cutting machine. The samples for scanning electron microscopy (SEM) grain size analyses, which were performed on crosssectional cuts perpendicular to the sample extrusion axis, were ground on $\mathrm{SiC}$ papers and polished mechanically using alumina compound and finally polished electrolytically. The foils for transmission electron microscopy (TEM) were prepared using a twin-jet electro-polishing device. The SEM observations, carried out on $70^{\circ}$ tilted samples with 0.5-1.0 $\mu \mathrm{m}$ scan step and $20 \mathrm{kV}$ accelerating voltage, were performed using a Tescan Lyra 3 FIB/SEM microscope equipped with a NordlysNano electron back-scattered diffraction (EBSD) detector. The evaluations of the grain size analyses were performed considering $15^{\circ}$ misorientation to be the limit between low-angle and high-angle grain boundaries. The foils prepared for TEM examinations were investigated using a Jeol $2100 \mathrm{~F}$ TEM machine operating at $200 \mathrm{kV}$.

The supplemental analyses of mechanical properties were performed via HV100 Vickers microhardness measurements carried out on cross-sections of samples cut by the CNC wire cutter and prepared similarly to samples for SEM observations. The applied load was $100 \mathrm{~N}$ and the indentation time was $15 \mathrm{~s}$; the measurements were performed using a Future Tech FM ARS 900 microhardness testing machine with a diamond indenter.

\section{Results and Discussion}

\section{A. Grain size}

The grain size analysis of the unprocessed material, showed quite coarse grains, several individual grains had the diameter of almost $150 \mu \mathrm{m}$. Nevertheless, the diameter of almost $70 \%$ of the grains was smaller than $50 \mu \mathrm{m}$ and the average diameter was less than $40 \mu \mathrm{m}$ (Fig. 2a). The analysis of the TCAP-processed sample revealed quite significant grain refinement. The average grain diameter after a single pass TCAP was lower than $6 \mu \mathrm{m}$ and the high imposed strain resulted in the refinement of the majority of the grains (almost $75 \%$ ) to the diameter of less than $5 \mu \mathrm{m}$ (Fig. 2b). A single pass TCAP thus exhibited a very high grain refining ability and is more efficient in imposing strain resulting in grain refinement than a single pass ECAP, as well as than two passes of ECAP performed by routes $\mathrm{A}$, as well as $\mathrm{Bc}[22,36]$.

The efficiency of the process is primarily given by the character of the process involving two stages of imposing strain - in the first deformation stage, the shear strain is mainly imposed by the twist to the sample peripheral regions, while in the second stage, the bending part of the channel imposes the strain primarily to the central region of the processed sample $[28,34,38]$. The positive effect of combining various SPD methods, passes and components together has already been proven $[39,40]$. However, TCAP provides a new combination of strain paths in a single pass, which is very efficient from the viewpoint of grain refinement [35].

a)

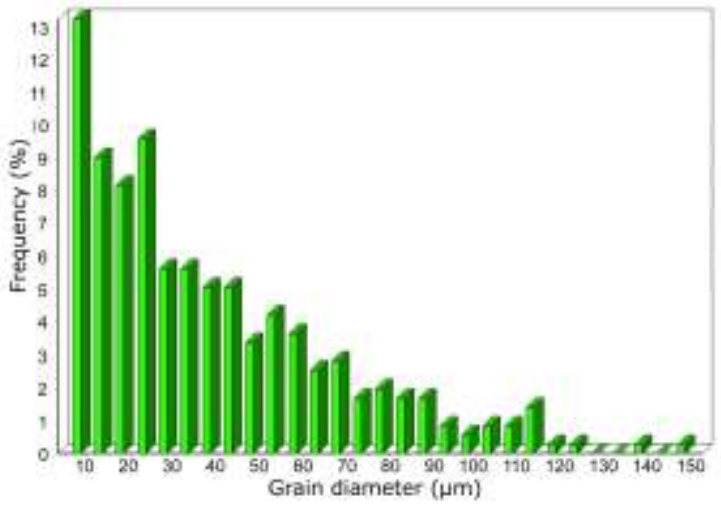

b)

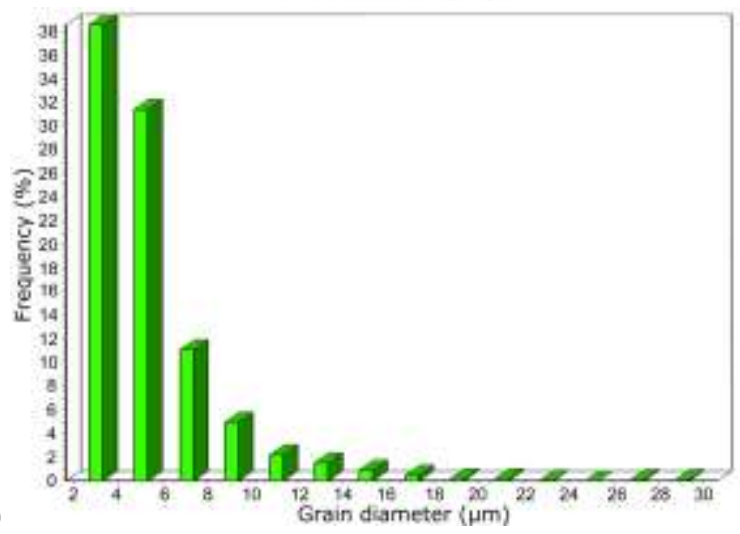

Figure 2. Grain size distributions for a) unprocessed state; b) sample after TCAP 


\section{B. Sub-structure evolution}

The substantial amount of the imposed strain was very favourable from the viewpoints of generation and movement of dislocations, which contributed to significant hardening of the processed material. A typical image of the structure right after processing is shown in Fig. 3a. As can be seen, the structure featured larger grains, originating in the unprocessed material, with highly developed sub-structures of dislocations and subgrains. In the upper right corner of Fig. 3a, a grain undergoing recovery can be noticed (evident grain boundary movement). A newly emerging and growing recovered grain can also be seen in Fig. 3b. The recovery process was most probably induced by the high pressure combined with the high imposed strain, which lowered the activation energy for recovery start [41]. The particular grain in Fig. 3b also evidently nucleated on a grain boundary, which is generally a location featuring higher energy.

The subgrains introduced by TCAP had the sizes smaller than the smallest sizes achievable by ECAP $(200-300 \mathrm{~nm})$ [19], which reveals a promising structure refining potential of this technology. The structure also featured the presence of fine secondary particles with the smallest having the diameters of around $10 \mathrm{~nm}$, which acted as barriers causing pinning of grain boundaries and dislocations, however, larger particles could also be seen. Despite the fact that larger particles do not significantly contribute to the pinning effect, they can be fragmented e.g. by dislocations moving through to smaller particles, which eventually contribute to hardening. This phenomenon was reported previously $[36,42]$.

a)

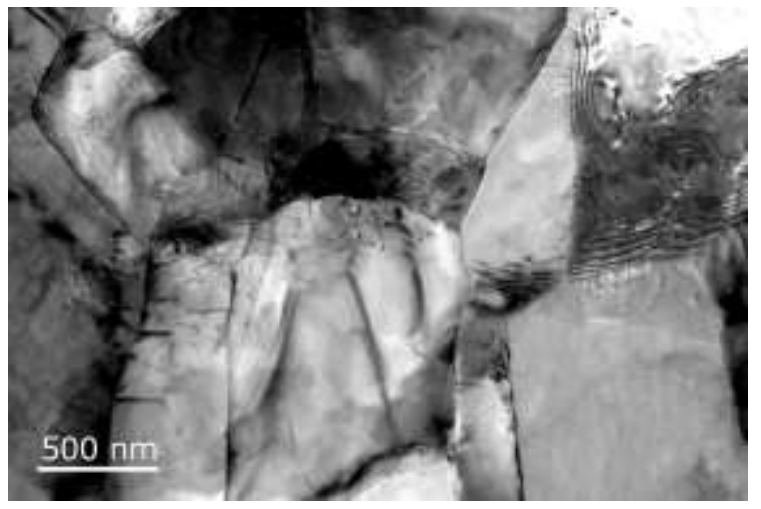

b)

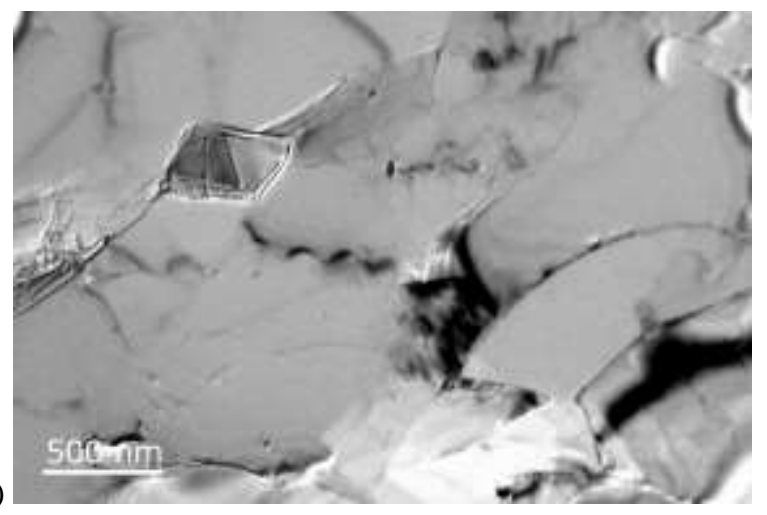

c)

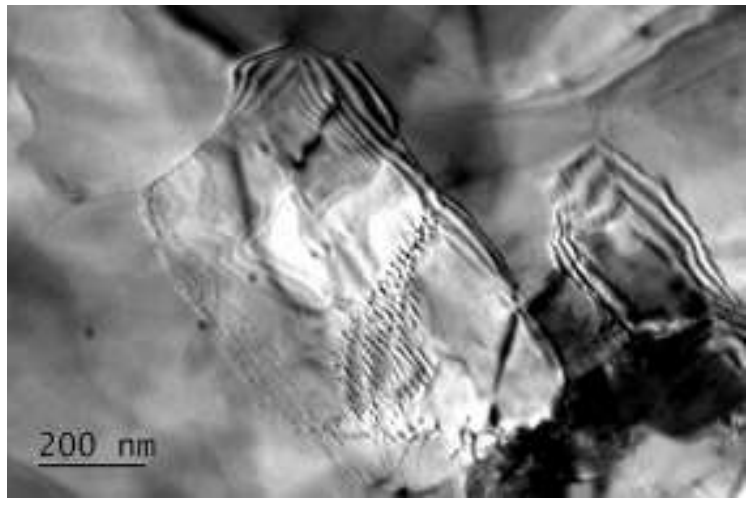

d)

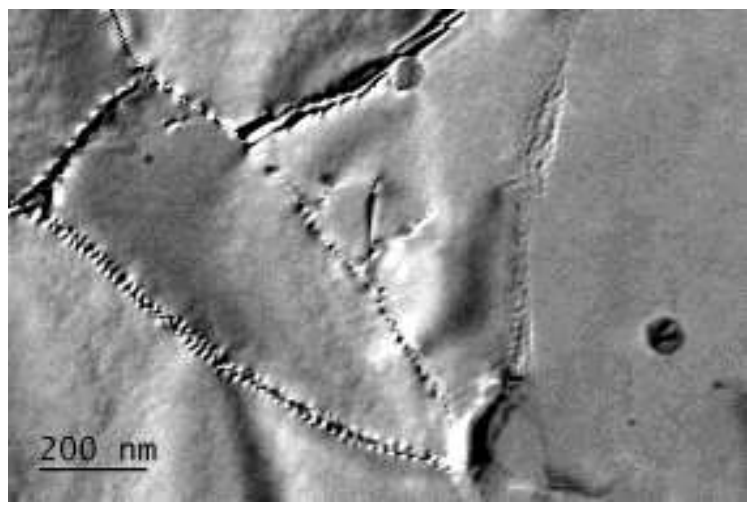

Figure 3. Sub-structure after TCAP (a), (b); Sub-structure after TCAP and one-year room temperature annealing (c), (d).

The sub-structure of the processed material was analysed again after one-year natural room temperature ageing. As can be seen in Figs. $3 \mathrm{c}$ and $3 \mathrm{~d}$, the structure after a year evidently featured a lower amount of dislocations and subgrains. Structures right after SPD processing by high amounts of shear strain are non-equilibrium and tend to undergo recovery processes (in time) [43]. They also contain a substantial number of triple junctions formed with low angle grain boundaries (LAGB), the movement of which also contributes to recovery processes [44-46]. In Fig. 3c, moving grain boundaries are obvious. The structure is also better recovered and features a significantly lower amount of dislocations, when compared to, for example, Fig. 3a, however, dislocation walls are still evident in certain locations. The Figure also shows fine precipitates. These can also be seen in Fig. 3d. This Figure shows recovered grains limited with dislocation-formed serrated boundaries. Formation of this type of boundary is a pre-final step before transformation of subgrains into full grains [47]. As can be seen, one of the serrated boundaries is from both its sides pinned by fine precipitates, which prevent dislocations movement and delay full recovery of the grain.

\section{Microhardness}

The graphical dependence in Fig. 4 shows the results of microhardness measurements performed along the crosssectional cuts of all the samples processed by TCAP, right after processing and after a year of natural ageing. The results 
are supplemented with the results of measurements performed on the original material, which exhibited the average microhardness of $44.6 \mathrm{HV}$. Evidently, the sample right after processing exhibited the highest HV values, the average microhardness within the sample was slightly above $91 \mathrm{HV}$. The analysed volume of the sample exhibited only slight differences between the minimum and maximum values and the microhardness distribution was quite homogenous. This significant microhardness increase was provided by the significant substructure development, increased number of generated dislocations and deformation induced precipitation, as described in the previous section [47].

Fig. 4 also shows the results of microhardness measurements for the sample after one-year ageing, which revealed slightly decreased values when compared to the sample right after processing. This finding is in accordance to the sub-structural observations, which showed recovered structure and decreased amount of dislocations comparing to the un-aged sample. However, the drop in HV was not so significant, most probably owing to the presence of strengthening precipitates, which also provided the pinning effect and made the recovery more difficult, as already mentioned.

Considering the results of sub-structure observations, together with the slight drop in microhardness, the assumption of probable increase in plastic properties can be made. Similar material behaviour was already reported for other materials processed by SPD [48]. Nevertheless, owing to the limited range of this paper, this investigation is going to be the theme for a subsequent study.

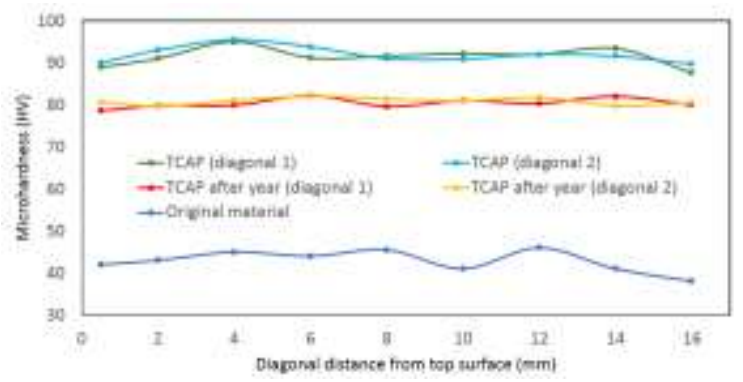

Figure 4. Comparison of microhardness for all investigated samples.

\section{Conclusion}

As shown by the results of this study, TCAP has a great potential as a strengthening technology. After a single pass, the majority of the grains refined to the average diameter of less than $5 \mu \mathrm{m}$ and the grains featured a significantly developed sub-structure of dislocations and subgrains. The energy accumulated in the material then resulted in a partial recovery of the structure after a one-year natural ageing at room temperature. The aged structure featured new grains recovered from subgrains and a decreased amount of dislocations. However, precipitation increased slightly.

All the phenomena influenced the microhardness development. Although the average HV values were almost doubled right after processing (increased to more than $90 \mathrm{HV}$ ), they decreased after the natural ageing due to the recovery processes, however, the drop was not very significant, which can be attributed to the increased precipitation. The phenomena occurring in the sub-structure of the aged material impart the notion of a notable increase in plastic properties, the analyses of which are going to be the topic for a subsequent study.

\section{Acknowledgment}

This paper was created with the support of the Project No. LO1203 "Regional Materials Science and Technology Centre - Feasibility Program" funded by Ministry of Education, Youth and Sports of the Czech Republic.

\section{References}

[1] I. Alexandrov, Y. Zhu, T. C. Lowe, R. Z. Valiev, "Severe plastic deformation: new technique for powder consolidation and grain size refinement," Powder Metall., vol. 41, no. 1, pp. 11-13, 1998.

[2] A. Moshkovich, I. Lapsker, Y. Feldman, L. Rapoport, "Severe plastic deformation of four FCC metals during friction under lubricated conditions," Wear, vol. 386, pp. 49-57, 2017.

[3] V. V. Stolyarov, Y. T. Zhu, T. C. Lowe, R. K. Islamgaliev, and R. Z. Valiev, "Two step SPD processing of ultrafine-grained titanium," Nanostructured Mater., vol. 11, no. 7, pp. 947-954, 1999.

[4] R. Kocich, L. Kunčická, C. F. Davis, T. C. Lowe, I. Szurman, A. Macháčková, "Deformation behavior of multilayered $\mathrm{Al}-\mathrm{Cu}$ clad composite during cold-swaging," Mater. Des., vol. 90, pp. 379-388, 2016.

[5] V. Kaune, C. Müller, "Formation of UFG-surface layers on a HSLA steel by a continuous Surface-SPD-Process," Mater. Sci. Eng. A, vol. 535, pp. 1-5, 2012.

[6] I. Nikulin, S. Malopheyev, A. Kipelova, R. Kaibyshev, "Effect of SPD and friction stir welding on microstructure and mechanical properties of Al-Cu-Mg-Ag sheets," Mater. Lett., vol. 66, no. 1, pp. 311-313, 2012.

[7] R. Kocich, L. Kunčická, D. Dohnalík, A. Macháčková, M. Šofer, "Cold rotary swaging of a tungsten heavy alloy: Numerical and experimental investigations," Int. J. Refract. Met. Hard Mater., vol. 61, pp. 264-272, 2016.

[8] R. Z. Valiev, I. P. Semenova, E. Jakushina, V. V. Latysh, H. Rack, T. C. Lowe, J. Petruzelka, L. Dluhos, D. Hrusak, J. Sochova, "Nanostructured SPD processed titanium for medical implants," Nanomater. by Sev. Plast. Deform. IV, vol. 584-586, pp. 49-54, 2008.

[9] F. Rubitschek, T. Niendorf, I. Karaman, H. J. Maier, "Corrosion fatigue behavior of a biocompatible ultrafine-grained niobium alloy in simulated body fluid," J. Mech. Behav. Biomed. Mater., vol. 5, no. 1, pp. 181-192, 2012.

[10] K. Surekha, A. Els-Botes, "Development of high strength, high conductivity copper by friction stir processing," Mater. Des., vol. 32, no. 2, pp. 911-916, 2011.

[11] M. Balog, P. Yu, M. Qian, M. Behulova, P. Svec, R. Cicka, "Nanoscaled Al-AlN composites consolidated by equal channel angular pressing (ECAP) of partially in situ nitrided Al powder," Mater. Sci. Eng. A, vol. 562, pp. 190-195, 2013.

[12] L. Kunčická, T. C. Lowe, C. F. Davis, R. Kocich, and M. Pohludka, "Synthesis of an Al/A12O3 composite by severe plastic deformation," Mater. Sci. Eng. A, vol. 646, pp. 234-241, 2015.

[13] N. Birbilis, K. D. Ralston, S. Virtanen, H. L. Fraser, C. H. J. Davies, "Grain character influences on corrosion of ECAPed pure magnesium," Corros. Eng. Sci. Technol., vol. 45, no. 3, pp. 224-230, 2010.

[14] J. Huot, N. Y. Skryabina, D. Fruchart, "Application of Severe Plastic Deformation Techniques to Magnesium for Enhanced Hydrogen Sorption Properties," Metals (Basel)., vol. 2, no. 4, pp. 329-343, 2012. 
[15] L. Kuncicka, R. Kocich, T. C. Lowe, "Advances in metals and alloys for joint replacement,” Prog. Mater. Sci., vol. 88, pp. 232-280, 2017.

[16] B. R. Sunil, A. A. Kumar, T. S. Sampath Kumar, U. Chakkingal, "Role of biomineralization on the degradation of fine grained AZ31 magnesium alloy processed by groove pressing," Mater. Sci. Eng. C, vol. 33, no. 3, pp. 1607-1615, 2013.

[17] X. N. Gu, N. Li, Y. F. Zheng, F. Kang, J. T. Wang, L. Ruan, "In vitro study on equal channel angular pressing AZ31 magnesium alloy with and without back pressure," Mater. Sci. Eng. B, vol. 176, no. 20, pp. 1802-1806, 2011.

[18] R. Kocich, M. Greger, A. Macháčková, "Finite element investigation of influence of selected factors on ECAP process," in METAL 2010: 19th international metallurgical and materials conference, 2010, pp. 166-171.

[19] R. Z. Valiev, T. G. Langdon, "Principles of equal-channel angular pressing as a processing tool for grain refinement," Prog. Mater. Sci., vol. 51, pp. 881-981, 2006.

[20] S. R. Kumar, K. Gudimetla, P. Venkatachalam, B. Ravisankar, K. Jayasankar, "Microstructural and mechanical properties of Al 7075 alloy processed by Equal Channel Angular Pressing," Mater. Sci. Eng. A, vol. 533, pp. 50-54, 2012.

[21] V. V Stolyarov, Y. T. Zhu, I. V. Alexandrov, T. C. Lowe, R. Z. Valiev, "Influence of ECAP routes on the microstructure and properties of pure Ti," Mater. Sci. Eng. A, vol. 299, no. 1-2, pp. 59-67, 2001.

[22] S. V. Dobatkin, J. A. Szpunar, A. P. Zhilyaev, J. Y. Cho, A. A. Kuznetsov, "Effect of the route and strain of equal-channel angular pressing on structure and properties of oxygen-free copper," Mater. Sci. Eng. A, vol. 462, no. 1-2, pp. 132-138, 2007.

[23] W. Z. Misiolek, M. Haase, N. Ben Khalifa, A. E. Tekkaya, M. Kleiner, "High quality extrudates from aluminum chips by new billet compaction and deformation routes," CIRP Ann. - Manuf. Technol., vol. 61, no. 1, pp. 239-242, 2012.

[24] R. Kocich, M. Kursa, A. Macháčková, "FEA of Plastic Flow in AZ63 Alloy during ECAP Process," Acta Phys. Pol. A, vol. 122, no. 3, pp. 581-587, 2012.

[25] E. Cerri, P. P. De Marco, P. Leo, "FEM and metallurgical analysis of modified 6082 aluminium alloys processed by multipass ECAP: Influence of material properties and different process settings on induced plastic strain," J. Mater. Process. Technol., vol. 209, no. 3, pp. 1550$1564,2009$.

[26] M. Haase, N. Ben Khalifa, A. E. Tekkaya, W. Z. Misiolek, "Improving mechanical properties of chip-based aluminum extrudates by integrated extrusion and equal channel angular pressing (iECAP)," Mater. Sci. Eng. A, vol. 539, pp. 194-204, 2012

[27] R. Pippan, S. Scheriau, A. Taylor, M. Hafok, A. Hohenwarter, A. Bachmaier, Saturation of Fragmentation During Severe Plastic Deformation, vol. 40. Palo Alto, CA: Annual reviews, 2010.

[28] R. Kocich, M. Greger, M. Kursa, I. Szurman, A. Macháčková, “Twist channel angular pressing (TCAP) as a method for increasing the efficiency of SPD,” Mater. Sci. Eng. A, vol. 527, no. 23, pp. 6386-6392, 2010

[29] D. Orlov, Y. Beygelzimer, S. Synkov, V. Varyukhin, N. Tsuji, Z. Horita, "Plastic flow, structure and mechanical properties in pure Al deformed by twist extrusion,” Mater. Sci. Eng. A, vol. 519, pp. 105-111, 2009.

[30] M. I. Latypov, M. G. Lee, Y. Beygelzimer, R. Kulagin, H. S. Kim, "On the simple shear model of twist extrusion and its deviations," Met. Mater. Int., vol. 21, no. 3, pp. 569-579, 2015.

[31] S. A. A. Akbari Mousavi, A. R. Shahab, M. Mastoori, "Computational study of Ti-6Al-4V flow behaviors during the twist extrusion process," Mater. Des., vol. 29, no. 7, pp. 1316-1329, 2008

[32] R. Kocich, J. Fiala, I. Szurman, A. Macháčková, M. Mihola, "Twistchannel angular pressing: effect of the strain path on grain refinement and mechanical properties of copper," J. Mater. Sci., vol. 46, no. 24, pp. 7865-7876, 2011.

[33] R. Kocich, A. Macháčková, L. Kunčická, "Twist channel multi-angular pressing (TCMAP) as a new SPD process: Numerical and experimental study," Mater. Sci. Eng. A, vol. 612, pp. 445-455, 2014.
[34] R. Kocich, L. Kunčická, M. Mihola, K. Skotnicová, "Numerical and experimental analysis of twist channel angular pressing (TCAP) as a SPD process," Mater. Sci. Eng. A, vol. 563, pp. 86-94, 2013.

[35] L. Kunčická, R. Kocich, P. Král, M. Pohludka, M. Marek, "Effect of strain path on severely deformed aluminium," Mater. Lett., vol. 180, pp. 280-283, 2016.

[36] R. Kocich, L. Kunčická, P. Král, A. Macháčková, "Sub-structure and mechanical properties of twist channel angular pressed aluminium," Mater. Charact., vol. 119, pp. 75-83, 2016.

[37] O. Engler, V. Randle, Introduction to Texture Analysis, Macrotexture, Microtexture, and Orientation Mapping, 2nd ed. Taylor and Francis Group, 2010.

[38] Y. Beygelzimer, V. Varyukhin, S. Synkov, D. Orlov, "Useful properties of twist extrusion," Mater. Sci. Eng. A, vol. 503, pp. 14-17, 2009.

[39] C. Wang, F. Li, Q. Li, J. Li, L. Wang, J. Dong, "A novel severe plastic deformation method for fabricating ultrafine grained pure copper," Mater. Des., vol. 43, pp. 492-498, 2013.

[40] A. Farhoumand, P. D. Hodgson, S. Khoddam, "Finite element analysis of plastic deformation in variable lead axisymmetric forward spiral extrusion," J. Mater. Sci., vol. 48, pp. 2454-2461, 2013.

[41] F. J. Humphreys, M. Hetherly, Recrystallization and Related Annealing Phenomena, 2nd ed. Oxford: Elsevier Ltd, 2004.

[42] A. Russell, K. L. Lee, Structure-Property Relations in Nonferrous Metals, 1st ed. New Jersey: John Wiley \& Sons, Inc., 2005.

[43] X. Sauvage, G. Wilde, S. V. Divinski, Z. Horita, R. Z. Valiev, "Grain boundaries in ultrafine grained materials processed by severe plastic deformation and related phenomena," Mater. Sci. Eng. A, vol. 540, pp. 1-12, 2012.

[44] T. Yu, D. A. Hughes, N. Hansen, X. Huang, "In situ observation of triple junction motion during recovery of heavily deformed aluminum," Acta Mater., vol. 86, pp. 269-278, 2015.

[45] T. Yu, N. Hansen, X. Huang, "Linking recovery and recrystallization through triple junction motion in aluminum cold rolled to a large strain," Acta Mater., vol. 61, no. 17, pp. 6577-6586, 2013.

[46] Q. Zhao, W. Jiang, D. J. Srolovitz, W. Bao, "Triple junction drag effects during topological changes in the evolution of polycrystalline microstructures," Acta Mater., vol. 128, pp. 345-350, 2017.

[47] B. Verlinden, J. Driver, I. Samajdar, R. D. Doherty, Thermo-mechanical processing of metallic materials. Amsterdam: Elsevier, 2007.

[48] R. Z. Valiev, I. V. Alexandrov, Y. T. Zhu, T. C. Lowe, "Paradox of Strength and Ductility in Metals Processed Bysevere Plastic Deformation,” J. Mater. Res., vol. 17, no. 1, pp. 5-8, 2002. 